\title{
Psychological Well-Being and Self-Efficacy in Life Skills among Italian Preadolescents with Positive Body Esteem: Preliminary Results of an Intervention Project
}

\author{
Elisabetta Sagone*, Maria Elvira De Caroli, Maria Luisa Indiana, \\ Salvatore Luciano Orazio Fichera \\ Department of Educational Sciences, University of Catania, Catania, Italy \\ Email: *esagone@unict.it
}

How to cite this paper: Sagone, E., De Caroli, M. E., Indiana, M. L., \& Fichera, S. L. O. (2018). Psychological Well-Being and Self-Efficacy in Life Skills among Italian Preadolescents with Positive Body Esteem: Preliminary Results of an Intervention Project. Psychology, 9, 1383-1396.

https://doi.org/10.4236/psych.2018.96084

Received: May 2, 2018

Accepted: June 26, 2018

Published: June 29, 2018

Copyright $\odot 2018$ by authors and Scientific Research Publishing Inc. This work is licensed under the Creative Commons Attribution International License (CC BY 4.0).

http://creativecommons.org/licenses/by/4.0/

\begin{abstract}
The main purpose of this project will be to increase the psychological well-being, self-efficacy in life skills, and body esteem in a group of Italian preadolescents who will participate in the life skills training. This project will be divided into three phases consisting of a verification of the changes that will take place following the realization of laboratory activities useful to enhance the psychological well-being of students in the scholastic context. For the first phase, an exploratory analysis of the main life skills, psychological well-being and body esteem levels was carried out with 49 participants aged 12 to 14 years recruited from three classes of a Public Junior School in Catania (Sicily, Italy). We used the Comprehensive Inventory of Thriving-CIT (Andolfi et al., 2017), the Perceived Self-efficacy Scales in Life Skills (Sagone \& Indiana, 2017), and the Body Esteem Scale (Confalonieri et al., 2008). Results showed positive correlations between perceived self-efficacy in life skills and almost all factors of psychological well-being, as well as positive correlations between perceived self-efficacy in life skills and body esteem; in detail, the weight satisfaction was mainly related with self-efficacy in managing of negative emotions and poorly with self-efficacy in interpersonal communication; in addition, the external evaluation from the others regarding own body image was positively correlated with self-efficacy in managing of positive emotions. In the intermediate phase, these preadolescents will attend the specific training about the life skills during the school time in order to increase these abilities and enhance well-being at school. At the third phase, we will compare the final results with the initial ones to verify the efficacy of the abovementioned training. This project will be useful to deep the role of life skills as me-
\end{abstract}


diators between psychological well-being and self-esteem.

\section{Keywords}

Psychological Well-Being, Self-Efficacy in Life Skills, Body Esteem, Italian Preadolescents

\section{Introduction}

The main purpose of this paper is to report the preliminary results of an intervention project about the increase of psychological well-being, perceived self-efficacy in life skills, and levels of body esteem in relation to the life skills training in the school context. The framework of this research is represented by factors that influence psychological well-being or thriving and development of perceived self-efficacy in life skills during the growth according the positive psychology approach. In this study, we adopted the assessment of psychological well-being in preadolescents using the combined conceptualizations expressed by Diener (2009) and Huppert \& So (2009): the components of life satisfaction, positive and negative feelings in relation to the hedonic approach (Diener, 1984; Diener, 1994; Diener, Suh, Lucas, \& Smith 1999) and the components of personal growth, mastery, optimistic orientation, positive relationships, and engagement, all concerning the eudaimonic perspective (see Ryff, 2014). This new way to deal with the valuation of psychological well-being originated by the use of one of the most recent measures created to assess all components of human positive functioning, that is, the Comprehensive Inventory of Thriving (CIT: Su, Tay, \& Diener, 2014). This inventory analyzed 1) the subjective well-being in terms of general life satisfaction and of presence of positive emotions more than negative ones (Diener, 1984); 2) the supportive and enriching relationships in terms of sense of community, belonging, support, and trust (Lucas \& Dyrenforth, 2006); 3) the engagement and environmental mastery in terms of enthusiasm experienced by individuals when they are totally absorbed in their activities (Ryff, 2014); 4) the meaning and purpose in life referred to the degree to which individuals believe that their life expresses a relevant meaning and a purpose to be achieved (Ryff, 2014); 5) a sense of achievement experienced in terms of skills, learning, self-efficacy, and self-worth linked to the awareness of having certain skills, adequately using them, and the feeling of accomplishment after utilizing those skills to solve problems; finally, this inventory included 6) the sense of control and autonomy concerning the beliefs of having control of one's own life (Scheier \& Carver, 1985; Ryan \& Deci, 2000) and 7) the optimistic orientation that "confers a mindset that has a positive outlook towards the future" (Wiese, Tay, Su, \& Diener, 2018: p. 129).

Recently, Andolfi and her colleagues created an Italian adaptation of CIT for Children (Andolfi, Tay, Confalonieri, \& Traficante, 2017), choosing as reference 
sample a large group of Italian children aged 8 to 11 years. The authors found positive correlations between the CIT-Child and MSLSS (Multidimensional Student's Life Satisfaction Scale: Huebner, 2004), as well as between the CIT-Child and SPANE (Scale of Positive and Negative Emotions: Diener, Wirtz, Tov, Kim-Prieto, Choi, Oishi, \& Biswas-Diener, 2010). In addition, Wiese et al. (2018) examined in a large sample of young adults the validity of factorial structure of the Comprehensive Inventory of Thriving (CIT: Su et al., 2014) across ten different countries (Argentina, Australia, China, Germany, India, Mexico, Russia, Singapore, Spain and Turkey), showing that it represents a good start for the comparison of the dimensions of psychological well-being across countries, despite the factor structure of the CIT could not be used in Argentina, China, and Mexico.

Another component of well-being was recognized as body esteem in preadolescents (see Bearman, Presnell, Martinez, \& Stice, 2006) related to body satisfaction (Alparone, Prezza, \& Camarda, 2000) and orientation to modify one's own body image (Mendelson, Mendelson, \& White, 2001). Body esteem is a multidimensional construct including self-evaluation of both appearance and weight. It refers to self-perception of one's own body appearance in relation to the opinions attributed by the others. For its multidimensionality (Mendelson et al., 2001), it is possible to evaluate the levels of body esteem with reference to three sub-dimensions: 1) BE-Appearance, that is, general feelings about appearance, 2) BE-Weight, in terms of weight satisfaction, and 3) BE-Attribution, named as external evaluation attributed by the others about one's body. These dimensions are strongly influenced by age and gender, as emerged in Yeh, Liou, \& Chien (2012), Ferreiro, Seoane, \& Senra (2012), and Bird, Halliwell, Diedrichs, \& Harcourt (2013). Mendelson et al. (2001) analyzed the body-esteem (using the BESAA-Body-Esteem Scale for Adolescents and Adults; see Mendelson, White, \& Balfour, 1995) in a large sample of Canadian boys and girls between 12 and 25 years of age: the authors found that girls expressed lower scores on BE-Appearance and BE-Weight than boys and these differences were maintained across the age range. So, girls were less satisfied with their body than boys. This datum represented a confirmation of previous results (Mendelson, White, \& Mendelson, 1996), according to which differences for gender in the self-evaluation of appearance emerged between 8 and 13 years of age and were due to a decline in positive self-evaluation in this period of growth for girls but not for boys. Recently, in Italian context, Confalonieri et al. (2008) validated a similar factorial structure of the Mendelson et al.'s scale (2001) but with only 14-item. The authors found that Italian adolescents with high levels of self-esteem (measured with the Rosenberg Self-Esteem Scale; see Prezza, Trombaccia, \& Armento, 1997) and with a good perception of their body (analyzed using the Body Image Satisfaction; Alparone et al., 2000) were more satisfied with their weight, appearance, and external evaluation by the others than those with low levels of self-esteem and negative perception of body image. Also, in 
this case, girls reported lower scores on BE-Weight and BE-Appearance than boys.

Several studies suggested the efficacy of prevention programs in school context and educational training focused on the increase of body esteem during this developmental age (Neumark-Sztainer, Paxton, Hannan, Haines, \& Story, 2006; Duncan, Al-Nakeeb, \& Nevill, 2009; Ross, Paxton, \& Rodgers, 2013; Diedrichs, Atkinson, Steer, Garbett, Rumsey, \& Halliwell, 2015; Halliwell, Yager, Paraskeva, Diedrichs, Smith, \& White, 2016). For example, Halliwell et al. (2016) carried out a study on the intervention program realized by teachers in order to improve the body satisfaction of English girls and boys of 9-10 years of age. Dividing total sample in the "intervention group" and "control group", the authors used the specific curriculum named as "Body Image in the Primary School", in which only children of intervention group participated in the body image lessons (see Hutchinson \& Calland, 2011). Using the Revised Body Esteem Scale (see Mendelson \& White, 1993), significant differences between girls and boys were noted: at baseline, girls reported lower levels of body esteem than boys but, after the intervention program, they efficiently increased their body esteem more than boys. Additionally, body esteem was significantly higher among girls of the intervention group than those of the control group. According to Halliwell et al. (2016), girls with low levels of body esteem at baseline reported the largest benefits from the intervention program. Also, Duncan et al. (2009) examined the effects of educational training on body esteem in 80 children aged $10-11$ years, predominantly recruited from a Primary School of Central England, using extracurricular sports/exercise activity and physical education lessons: so, children of the intervention group (especially, girls) increased their body esteem more than those of control group. Furthermore, Ross et al. (2013) found the increase of body satisfaction among primary school Australian girls (aged $11-12$ years), noticing that the intervention group took into consideration positive image of their body and positive attitudes as "thin-ideal internalization", "body comparison", and "self-esteem". Recently, Diedrichs et al. (2015) tested the effectiveness of a brief school-based body image intervention (named as "Dove Confident Me: Single Session") in a large group of 1707 British adolescents, with the main objective to improve the body satisfaction and to decrease the risk factors related to a negative perception of body image. The findings revealed that this intervention showed short-term benefits only for girls' body image and eating disorders symptoms.

Scientific literature underlined that, by means of these interventions, it is possible to enhance psychological well-being and body esteem in pre-adolescents, adopting a positive approach mediated by the sense of self-efficacy useful to an optimal development of individual. Among the components directly connected to psychological well-being in terms of "thriving", it is so possible to recognize the perceived self-efficacy (see Bandura, 1998): this psychological construct is defined by "beliefs in one's capabilities to organize and execute the courses of 
action required to produce given levels of attainments" (Bandura, 1998). Referring to this approach, self-efficacy beliefs are connected to specific domains of the individual's functioning: 1) self-efficacy in the expression of positive emotions and the managing of negative feelings (see Caprara, Gerbino, \& Delle Fratte, 2001; Sagone \& Indiana, 2017), 2) self-efficacy in interpersonal and social communication, relating to the individual's skill to efficiently communicate with the others, to actively participate in group setting and to establish good relationships with others (Pastorelli, Vecchio, \& Boda, 2001), and 3) self-efficacy in problem solving useful to solve problems in a different and creative way. These individual's aspects were defined as "life skills", that are described as a set of "abilities for adaptive and positive behavior that enable individuals to deal efficiently with the demands and challenges of everyday life" (World Health Organization, 2003). In detail, as reported by Sagone \& Indiana (2017), "life skills are psychosocial and interpersonal competencies that help people making informed decisions (decision making), solving problems (problem solving), thinking critically and creatively (critical and creative thinking), communicating efficiently (efficacy communication), building healthy relationships (interpersonal relationships), get involved with others (empathy), knowing themselves, recognizing feelings as it occur and discriminating between them (self-awareness), and, finally, managing emotions and stress" (2017, p. 2229). It is demonstrated that perceived self-efficacy in daily life is directly linked to psychological well-being of individuals in different contexts. So, De Caroli \& Sagone (2014) studied the relationship between generalized self-efficacy and psychological well-being in a sample of highly and lowly efficient Italian adolescents, noticing significant and positive relationships between self-efficacy and environmental mastery, personal growth, and self-acceptance.

As well as for the body esteem, the presence of life skills programs has important benefits on psychological well-being of preadolescents. For example, McVey, Davis, Tweed, \& Shaw (2004) evaluated the efficacy of life-skills promotion program useful to enhance the body image satisfaction (measured with the SIQYA of Petersen, Schulenberg, Abramowitz, Offer, \& Jarcho, 1984) and global self-esteem (with the Rosenberg's scale) and to reduce negative eating attitudes and feelings of perfectionism in a sample of 258 Canadian preadolescent girls. This life skills program was focused on the application of a specific curriculum entitled "Every Body is a Somebody" and articulated in six weekly 50-min sessions about the following themes: "media influences", "enhancing self-esteem and body image", "body size acceptance", "healthy living”, "stress management", and "positive relationships". The results confirmed that this program modified the abovementioned aspects.

Considering the efficacy of all these programs during the adolescence, the current study will try to improve the psychological well-being, self-efficacy in life skills and levels of body esteem in a group of Italian preadolescents engaged in the life skills training. The duration of this project will be from October 2017 to 
June 2018 and will be divided into three phases functional to verify the changes that will take place following the realization of specific activities in eight sessions useful to enhance the psychological well-being of preadolescents at school.

\section{Method}

\subsection{Purpose of Study}

The main purpose of this project will be to improve the psychological well-being, self-efficacy in life skills, and perception of body image in a group of Italian pre-adolescents who will participate in an intervention-project focused on the life skills training. At this first phase (pre-training), we realized the exploratory analysis of preliminary data, formulating the following hypotheses:

$\mathrm{H}_{1}$ ) preadolescents with high self-efficacy in life skills would report higher levels of psychological well-being than those with low levels of self-efficacy;

$\mathrm{H}_{2}$ ) preadolescents with high self-efficacy in life skills would express higher body esteem than those with low levels of self-efficacy;

$\mathrm{H}_{3}$ ) considering the differences for gender, girls would confirm lower levels of body esteem (as noted in Mendelson's and Confalonieri's researches), psychological well-being (as reported in De Caroli \& Sagone, 2014), and self-efficacy in life skills (regulation of negative emotions) than boys (as indicated in Caprara et al., 2001 and recently in Sagone \& Indiana, 2017).

\subsection{Participants}

The sample consisted of 49 Italian preadolescents randomly recruited from three classes of a Public Junior School in Catania ( $\mathrm{n}=26$ boys; $\mathrm{n}=23$ girls), Sicily, Italy. Their age range was from 12 to 14 years. Other socio-demographic information were obtained but not included into these preliminary analyses. Parental consent for the underage adolescents' participation to this study was requested and obtained in accordance with the requirements of privacy and anonymity laid down by Italian Law (Law Decree DL. 196/2003).

\subsection{Measures and Procedure}

For data collection we used a self-report questionnaire for socio-demographic information and the following measures: 1) the Italian adaptation of the Comprehensive Inventory of Thriving, CIT-Child (see Su, Tay, \& Diener, 2014; Andolfi, Tay, Confalonieri, \& Traficante, 2017), 2) the Perceived Self-efficacy Scales in Life Skills (see Sagone \& Indiana, 2017), and 3) the Italian validation of Body Esteem Scale for Adolescents-BES (see Mendelson, Mendelson, \& White, 2001; Confalonieri, Gatti, Ionio, \& Traficante, 2008). These measures were administered in a group setting during the school activities.

The Comprehensive Inventory of Thriving-CIT consisted of 36 items (Andolfi et al., 2017) useful to measure the factors of support (e.g., "There are people I can depend on to help me"), respect (e.g., "People are polite to me"), loneliness (e.g., "I feel left out"), belonging (e.g., "I feel a sense of belonging in my coun- 
try"), engagement (e.g., "I get excited when I work on something"), skills (e.g., "I use my skills a lot in my everyday life"), learning (e.g., "Learning new things is very important for me"), self-worth (e.g., "What I do in life is valuable and worthwhile"), optimism (e.g., "I am optimistic about my future"), life satisfaction (e.g., "I am satisfied with my life"), positive and negative feelings (e.g., "I feel happy/unhappy most of the time"). Each CIT-Child item was scored on a scale ranging from 1 to 5 points, where the value of 1 corresponds to "fully disagree" and that of 5 corresponds to "strongly agree". The internal consistency of CIT, using the Cronbach's alpha coefficient, was largely satisfactory $(\alpha=.90)$.

The Perceived Self-Efficacy Scales in Life Skills were grouped in 50 statements (Caprara et al., 2001; Pastorelli et al., 2001; Sagone \& Indiana, 2007) selected for this sample from those recently used by Sagone \& Indiana (2007) to analyze the ability to regulate and manage the expression of positive emotions (PSES_PE with 7 items, e.g., "I can feel gratified over achieving what I set out to do") and negative emotions (PSES_NE with 13 statements, e.g., "I can get over irritation quickly for wrongs I have experienced"), the ability to communicate in interpersonal and social relationships (PSES_IC/SC with 19 items, e.g., "How much do you think to be able to avoid heated disputes during a meeting?"), and the ability to respond in problem-solving situations in efficient way (PSES_PS with 11 statements, e.g., "How much do you think to be able to recognize alternative and positive solutions for problems?"). Preadolescents were asked to indicate how much they felt themselves able in a range between 1 (equal to "not at all efficient") and 5 intervals (equal to "completely efficient") for each considered situation. The internal consistency of Perceived Self-Efficacy Scales in Life Skills was mostly satisfactory $(\alpha=.87)$.

The Body Esteem Scale-BES (Confalonieri et al., 2008) consisted of 14 items included into three subscales useful to measure the self-perception of one's own body (appearance: e.g. "I wish I looked better", “There are lots of things I'd change about my looks" reverse item), the satisfaction for one's own weight (weight satisfaction: e.g. "I am satisfied with my weight", "Weighing myself depresses me" reverse-item), and the evaluation attributed by the others about one's own body and appearance (attribution: e.g. "Other people consider me good looking", "My looks help me to get dates"). Participants filled out this measure using a 5-point Likert scale ranging from 0 (corresponding to "never") to 4 intervals (corresponding to "always"). There were seven negative items that were reverse-scored. The internal consistency of BES was partially satisfactory ( $\alpha$ $=.60$ ), if compared to Italian sample used by Confalonieri et al. (2008).

The experimental design of this project will be articulated in three phases. After the analysis of the psychological well-being, self-efficacy in life skills, and levels of body esteem expressed by the randomly chosen participants (first phase; pre-training), the activities functional to increase the psychological dimensions analyzed in the first phase will be carried out during the life skills training in school context (intermediate phase); subsequently, the measures used at the start 
of the project will be re-administered to all participants in order to verify the efficacy of the training (post-training).

\subsection{Statistical Analysis}

The examination of the statistical significance of results was carried out using the SPSS 20 software (Statistical Package for Social Sciences) with the following tests: t-Student and Pearson's linear correlations. Gender of participants was used as independent variable while mean scores of psychological well-being, self-efficacy in life skills, and factors of body esteem were used as dependent variables.

\section{Results}

Descriptive analyses for CIT-Child were reported in Table 1 and comparable to those found by Andolfi and her colleagues' Italian validation (2017). These results showed that preadolescents obtained higher mean scores in dimensions of positive feelings $(\mathrm{M}=4.10, \mathrm{sd}=.80)$, life satisfaction $(\mathrm{M}=4.01$, sd $=.78)$, engagement $(\mathrm{M}=3.97, \mathrm{sd}=.76)$, and support $(\mathrm{M}=3.81, \mathrm{sd}=.87)$ than the others.

It meant that this group of participants in the initial phase of training exhibited a positive condition of well-being mainly characterized by positive affectivity, high satisfaction with their life, great personal engagement, and high perceived support by the others. Contrary to what emerged in Andolfi et al.'s study (2017), differences for gender in our study were not found.

About the self-efficacy in life skills, measured at the initial phase of project, results indicated that these preadolescents reached high mean scores in PSES_IC/SC $(M=69.35$, sd $=9.3)$, average mean scores in PSES_PS $(M=39.89$, sd $=5.6)$ and PSES_NE $(M=42.67, \mathrm{sd}=8.4)$, and low mean scores in PSES_PE

Table 1. Descriptive analyses for CIT-Child.

\begin{tabular}{cccc}
\hline Dimensions & Subscales & Means & SD \\
\hline \multirow{2}{*}{ Relationships } & I. Support & 3.80 & .96 \\
& II. Respect & 3.12 & .99 \\
Engagement & III. Loneliness & 3.48 & 1.11 \\
& IV. Belonging & 3.78 & .75 \\
V. Personal engagement & VI. Skills & 3.98 & .75 \\
Mastery & VII. Learning & 3.69 & .91 \\
& VIII. Self-worth & 3.66 & .85 \\
Optimism & IX. Optimistic orientation & 3.71 & .75 \\
& X. Life satisfaction & 3.69 & .78 \\
& XI. Positive feelings & 4.01 & .80 \\
& XII. Negative feelings & 4.10 & 1.11 \\
\hline
\end{tabular}


$(M=29.92$, sd $=4.3)$. Significant differences for gender in PSES_PS $\left(t_{(47)}=2.642\right.$, $p=.012)$ and PSES_PE $\left(t_{(47)}=-2.075, p=.03\right)$ were noted: so, boys perceived themselves as more efficient in solution of problems and difficulties than girls, and girls perceived themselves as more efficient in managing of positive emotions than boys (Table 2).

Referring to the body esteem, valued at the initial phase of training, preadolescents obtained higher mean scores of weight satisfaction $(\mathrm{M}=2.32$, $\mathrm{sd}=.98)$ than those of appearance $(\mathrm{M}=2.04, \mathrm{sd}=.98)$ and body attribution $(\mathrm{M}=2.01$, sd $=.92$ ), underlining the absence of significant differences for gender. These results are similar to those obtained by Confalonieri et al. (2008) only with reference to the external attribution: so, boys and girls exhibited the same attitudes in relation to the other people's evaluations about their own body, resulting scarcely worried for social desirability in this developmental period. For the two remaining factors (weight satisfaction and appearance), differences for gender emerged only in Confalonieri et al.'s Italian validation of BES in favor of boys.

In order to verify the $\mathrm{H}_{1}$, linear correlations between perceived self-efficacy in life skills and psychological well-being were analyzed (Table 3). In detail, PSES_IC/SC was correlated with the factors of positive feelings, support, respect, engagement, learning, optimism, belonging, and skills. PSES_NE was correlated with life satisfactions, respect, engagement, self-worth, optimism, learning, belonging, and positive feelings. PSES_PE was correlated with almost all the factors of psychological well-being. Finally, PSES_PS was mainly related with the factor of learning and poorly with engagement, self-worth, and optimism.

It meant that the more these preadolescents perceived themselves as efficient in communicating with others, in solving problems, in managing of positive and negative emotions, the more they reached high levels of psychological well-being, in terms of engagement, mastery, optimistic orientation, life satisfaction, and positive feelings.

In order to corroborate the $\mathrm{H}_{2}$, linear correlations between perceived self-efficacy in life skills and factors of body esteem were examined (Table 4); so,

Table 2. Descriptive analyses for self-efficacy in life skills: differences for gender.

\begin{tabular}{|c|c|c|c|}
\hline \multirow{2}{*}{ Life skills } & \multicolumn{3}{|c|}{ Differences for gender } \\
\hline & Participants & Means & Std. deviation \\
\hline \multirow{2}{*}{ PSES_PS* } & Boys & 41.76 & 4.8 \\
\hline & Girls & 37.78 & 5.8 \\
\hline \multirow{2}{*}{ PSES_IC/SC } & Boys & 69.35 & 9.5 \\
\hline & Girls & 69.34 & 9.1 \\
\hline \multirow{2}{*}{ PSES_NE } & Boys & 44.46 & 9.6 \\
\hline & Girls & 41.65 & 6.3 \\
\hline \multirow{2}{*}{ PSES_PE* } & Boys & 28.76 & 5.1 \\
\hline & Girls & 31.21 & 2.6 \\
\hline
\end{tabular}


Table 3. Linear correlations between self-efficacy in life skills and psychological well-being.

\begin{tabular}{|c|c|c|c|c|c|c|c|c|c|c|c|c|}
\hline \multirow{2}{*}{ Life skills } & \multicolumn{12}{|c|}{ CIT-Child } \\
\hline & I. & II. & III. & IV. & V. & VI. & VII. & VIII. & XI. & $\mathrm{X}$. & XI. & XII. \\
\hline \multirow{2}{*}{ PSES_PS } & .25 & .26 & -.01 & .14 & $.31^{\star}$ & .27 & $.44^{* *}$ & $.32^{\star}$ & $.35^{\star}$ & .25 & .22 & .01 \\
\hline & ns & ns & ns & ns & .03 & ns & .001 & .025 & .015 & ns & ns & ns \\
\hline \multirow{2}{*}{ PSES_IC/ SC } & $.58^{\star \star}$ & $.53^{\star *}$ & .12 & $.29^{\star}$ & $.44^{\star *}$ & $.29^{\star}$ & $.63^{\star *}$ & $.52^{\star *}$ & $.56^{\star *}$ & .25 & $.37^{\star}$ & .16 \\
\hline & .000 & .000 & ns & .045 & .001 & .042 & .000 & .000 & .000 & ns & .009 & ns \\
\hline \multirow{2}{*}{ PSES_NE } & .21 & $.39^{*}$ & .14 & $.34^{*}$ & $.49^{* *}$ & .23 & $.34^{*}$ & $.50^{\star *}$ & $.39^{* *}$ & $.37^{\star}$ & $.35^{\star}$ & .08 \\
\hline & ns & .006 & ns & .015 & .000 & ns & .016 & .000 & .006 & .010 & .015 & ns \\
\hline \multirow{2}{*}{ PSES_PE } & $.56^{\star *}$ & $.54^{* *}$ & .17 & $.36^{*}$ & $.43^{\star *}$ & .24 & $.65^{\star *}$ & $.51^{\star *}$ & $.53^{\star *}$ & $.49^{\star *}$ & $.51^{\star *}$ & .09 \\
\hline & .000 & .000 & ns & .011 & .002 & ns & .000 & .000 & .000 & .000 & .000 & ns \\
\hline
\end{tabular}

Table 4. Linear correlations between self-efficacy in life skills and body esteem.

\begin{tabular}{cccc}
\hline \multirow{2}{*}{ Life skills } & \multicolumn{3}{c}{ Body Esteem } \\
\cline { 2 - 4 } & Weight Satisfaction & Body Attribution & Appearance \\
\hline \multirow{2}{*}{ PSES_PS } & $\mathrm{ns}$ & .07 & .02 \\
& $.35^{\star}$ & $\mathrm{Ns}$ & $\mathrm{ns}$ \\
PSES_IC/SC & .015 & .04 & -.10 \\
& $.43^{* *}$ & $\mathrm{Ns}$ & $\mathrm{ns}$ \\
PSES_NE & .002 & .21 & -.11 \\
& .16 & $\mathrm{Ns}$ & $\mathrm{ns}$ \\
PSES_PE & $\mathrm{ns}$ & $.31^{*}$ & -.04 \\
& & .033 & $\mathrm{~ns}$ \\
\hline
\end{tabular}

PSES_NE was mainly related with the factor of weight satisfaction, as well as PSES_IC/SC was poorly related with the same factor; additionally, PSES_PE was related with the body attribution. It meant that the more these preadolescents perceived themselves as efficient in managing of negative emotions and in communicating with the others, the more they were satisfied with their own weight; further, the more these preadolescents perceived themselves as efficient in managing of positive emotions, the more they were satisfied with the external evaluation about their own body.

\section{Discussion}

The purpose of this study was to know the initial situation of preadolescents randomly chosen to participate in life skills trainings and to investigate the relationship among perceived self-efficacy in life skills, well-being in the integrated perspective of thriving, and levels of body esteem. This paper collected the preliminary results of the first phase of an intervention-project focused on the implementation of life skills during the developmental age (see Botvin \& Griffin, 
2004). Preadolescents who perceived themselves as efficient in the ability to solve problems, to manage positive and negative emotions, and to create good relationships with others are those who exhibited great well-being. Other positive correlations between self-efficacy in life skills and body esteem were noted, suggesting that preadolescents who perceived themselves as efficient in different life skills are those who expressed a positive view of themselves and of their own body, also in relation to the others' expectations. At this first phase of project results confirmed the initial hypotheses $\left(\mathrm{H}_{1}\right.$ and $\left.\mathrm{H}_{2}\right)$ and provided relevant guidelines for the specific educational programs at school useful to promote psychological well-being during the adolescence. These evidences and other findings reported in previous studies suggest us to adopt a groups-based training about the "body theme" to work mainly on external expectations (BE-Attribution) and social desirability (BE-Appearance), using activities focused on perceived self-efficacy to solve problems (as, for example, to be able to modify own body if individual doesn't like it) and to efficiently manage emotional and critical situations. These activities could be realized with the help of teachers specialized in physical activity and non-competitive exercises, also controlling the attitudes referred to the body esteem for the body mass index of participants. Furthermore, these activities could be included into a specific curriculum focused on the analysis of life skills to enhance the "body esteem" using the focus group's activity and to increase the psychological well-being at school, adopting methods of role-playing and group-discussions about the role of self-efficacy in various aspects of daily life. As reported by Srikala \& Kishore Kumar (2010), the application of life skills educational programs in Indian school context can produce success and enhance self-esteem of students: so, a sample of 605 Indian adolescents (aged between 14 and 16 years) who attend these programs increase their levels of self-esteem, use adaptive coping strategies, and tend to develop a positive climate with their teachers. These aspects contribute to enrich and deep psychological well-being of students; as Bandy \& Moore (2011) suggested in the "Fact Sheet" of Child Trends, the early identification of intervention strategies and practices that promote social skills can increase the likelihood of positive outcomes for children and adolescents and reduce the occurrence of negative outcomes.

Considering the $\mathrm{H}_{3}$, differences for gender were confirmed only in relation to perceived self-efficacy in life skills: boys perceived themselves as efficient in solution of problems and difficulties and girls perceived themselves as efficient in managing of positive emotions. These evidences are in line with the results obtained by Sagone \& Indiana (2017) and by Caprara et al. (2001) with reference to the sex differences about the perceived self-efficacy in regulation and managing of emotions.

Further results will be elaborated from the final phase of project (post-training) because these preadolescents will attend the specific training about the life skills during the school time in order to improve the abovemen- 
tioned abilities and increase well-being at school linked to their body esteem. At the final phase, we will analyze again the same dimensions with the previous measures to verify the efficacy of this training.

The reduced amount of investigations focused on the relationship existing among perceived self-efficacy in life skills, body esteem levels, and well-being in Italian healthy preadolescents constituted the relevance of this paper. Additionally, the findings of the current study and those of other researchers permitted to think about "the role of educational programs based on the development of life skills, demonstrated as widely efficient in various areas of well-being promotion in adolescence" (Sagone \& Indiana, 2017).

\section{References}

Alparone, F. R., Prezza, M., \& Camarda, P. (2000). Measures of Body Image in the Developmental Age. Bollettino di Psicologia Applicata, 231, 25-35.

Andolfi, V. R., Tay, L., Confalonieri, E., \& Traficante, D. (2017). Assessing Well-Being in Children: Italian Adaptation of the Comprehensive Inventory for Children (CIT-CHILD). TPM, 24, 1-19.

Bandura, A. (1998). Health Promotion from the Perspective of Social Cognitive Theory. Psychology and Health, 13, 623-649. https://doi.org/10.1080/08870449808407422

Bandy, T., \& Moore, K. A. (2011). What Works for African American Children and Adolescents: Lessons from Experimental Evaluations of Programs and Interventions. Washington DC: Child Trends.

Bearman, S. K., Presnell, K., Martinez, E., \& Stice, E. (2006). The Skinny on Body Dissatisfaction: A Longitudinal Study of Adolescent Girls and Boys. Journal of Youth and Adolescence, 35, 217-229. https://doi.org/10.1007/s10964-005-9010-9

Bird, E. L., Halliwell, E., Diedrichs, P. C., \& Harcourt, D. (2013). Happy Being Me in the UK: A Controlled Evaluation of a School-Based Body Image Intervention with Pre-Adolescent Children. Body Image, 10, 326-334.

https://doi.org/10.1016/j.bodyim.2013.02.008

Botvin, G. J., \& Griffin, K. W. (2004). Life Skills Training: Empirical Findings and Future Directions. Journal of Primary Prevention, 25, 211-232.

Caprara, G. V., Gerbino, M., \& Delle Fratte, A. (2001), Autoefficacia interpersonale. In G. V. Caprara (Ed.), La valutazione dell'autoefficacia. Costrutti e strumenti (pp. 51-62). Trento: Erickson.

Confalonieri, E., Gatti, E., Ionio, C., \& Traficante, D. (2008). Body Esteem Scale: A Validation on Italian Adolescents. TPM, 15, 153-165.

De Caroli, M. E., \& Sagone, E. (2014). Generalized Self-Efficacy and Well-Being in Adolescents with High vs. Low Scholastic Self-efficacy. Procedia-Social and Behavioral Sciences, 141, 867-874. https://doi.org/10.1016/j.sbspro.2014.05.152

Diedrichs, P. C., Atkinson, M. J., Steer, R. J., Garbett, K. M., Rumsey, N., \& Halliwell, E. (2015). Effectiveness of a Brief School-Based Body Image Intervention "Dove Confident Me: Single Session" When Delivered by Teachers and Researchers: Results from a Cluster Randomised Controlled Trial. Behaviour Research and Therapy, 74, 94-104. https://doi.org/10.1016/j.brat.2015.09.004

Diener, E. (1984). Subjective Well-Being. Psychological Bulletin, 95, 542-575. https://doi.org/10.1037/0033-2909.95.3.542 
Diener, E. (1994). Assessing Subjective Well-Being: Progress and Opportunities. Social Indicators Research, 31, 103-157. https://doi.org/10.1007/BF01207052

Diener, E. (2009). Subjective Well-Being. In E. Diener (Ed), The Science of Well-Being (Vol. 37, pp. 11-58). New York. NY: Springer. https://doi.org/10.1007/978-90-481-2350-6_2

Diener, E., Suh, E. M., Lucas, R. E., \& Smith, H. L. (1999). Subjective Well-Being: Three Decades of Progress. Psychological Bulletin, 125, 276-302. https://doi.org/10.1037/0033-2909.125.2.276

Diener, E., Wirtz, D., Tov, W., Kim-Prieto, C., Choi, D. W., Oishi, S., \& Biswas-Diener, R. (2010). New Well-Being Measures: Short Scales to Assess Flourishing and Positive and Negative Feelings. Social Indicators Research, 97, 143-156. https://doi.org/10.1007/s11205-009-9493-y

Duncan, M. J., Al-Nakeeb, Y., \& Nevill, A. M. (2009). Effects of a 6-Week Circuit Training Intervention on Body Esteem and Body Mass Index in British Primary Schoolchildren. Body Image, 6, 216-220. https://doi.org/10.1016/j.bodyim.2009.04.003

Ferreiro, F., Seoane, G., \& Senra, C. (2012). Gender-Related Risk and Protective Factors for Depressive Symptoms and Disordered Eating in Adolescence: A 4-Year Longitudinal Study. Journal of Youth and Adolescence, 41, 607-622. https://doi.org/10.1007/s10964-011-9718-7

Halliwell, E., Yager, Z., Paraskeva, N., Diedrichs, P. C., Smith, H., \& White, P. (2016). Body Image in Primary Schools: A Pilot Evaluation of a Primary School Intervention Program Designed by Teachers to Improve Children's Body Satisfaction. Body Image, 19, 133-141. https://doi.org/10.1016/j.bodyim.2016.09.002

Huebner, E. S. (2004). Research on Assessment of Life Satisfaction of Children and Adolescents. Social Indicators Research, 66, 3-33. https://doi.org/10.1007/978-1-4020-2312-5_2

Huppert, F. A., \& So, T. (2009). What Percentage of People in Europe Are Flourishing and What Characterized Them. IX ISQOLS Conference, July, 1-7.

Hutchinson, N., \& Calland, C. (2011). Body Image in the Primary School. London: Taylor \& Francis.

Lucas, R. E., \& Dyrenforth, P. S. (2006). Does the Existence of Social Relationships Matter for Subjective Well-Being? In K. D. Vohs, \& E. J. Finkel (Eds.), Self and Relationships: Connecting Intrapersonal and Interpersonal Processes (pp. 254-273). New York, NY: Guilford Press.

McVey, G. L., Davis, R., Tweed, S., \& Shaw, B. F. (2004). Evaluation of a School-Based Program Designed to Improve Body Image Satisfaction, Global Self-Esteem, and Eating Attitudes and Behaviors: A Replication Study. International Journal of Eating Disorders, 36, 1-11. https://doi.org/10.1002/eat.20006

Mendelson, B. K., Mendelson, M. J., \& White, D. R. (2001). Body Esteem Scale for Adolescents and Adults. Journal of Personality Assessment, 76, 90-106. https://doi.org/10.1207/S15327752JPA7601_6

Mendelson, B. K., White, D. R., \& Balfour, L. (1995). The Body-Esteem Scale for Adolescents and Adults. Unpublished Manuscript, Montreal, Canada: Concordia University.

Mendelson, B. K., White, D. R., \& Mendelson, M. J. (1996). Self-Esteem and Body Esteem: Effects of Gender, Age, and Weight. Journal of Applied Developmental Psychology, 17, 321-346. https://doi.org/10.1016/S0193-3973(96)90030-1

Mendelson, B., \& White, D. (1993). Manual for the Body Esteem Scale-Children. Montreal, Canada: Center for Research in Human Development, Concordia University. 
Neumark-Sztainer, D., Paxton, S. J., Hannan, P. J., Haines, J., \& Story, M. (2006). Does Body Satisfaction Matter? Five-Year Longitudinal Associations between Body Satisfaction and Health Behaviors in Adolescent Females and Males. Journal of Adolescent Health, 39, 244-251. https://doi.org/10.1016/j.jadohealth.2005.12.001

Pastorelli, C., Vecchio, G. M., \& Boda, G. (2001). Autoefficacia nelle life skills: Soluzione dei problemi e comunicazione interpersonale. In G. V. Caprara (Ed.), La valutazione dell'autoefficacia. Costrutti e strumenti (pp. 137-146). Trento, Italy: Erickson.

Petersen, A. C., Schulenberg, J. E., Abramowitz, R. H., Offer, D., \& Jarcho, H. D. (1984). A Self-Image Questionnaire for Young Adolescents (SIQYA): Reliability and Validity Studies. Journal of Youth and Adolescence, 13, 93-111.

https://doi.org/10.1007/BF02089104

Prezza, M., Trombaccia, F. R., \& Armento, L. (1997). La scala dell'autostima di Rosenberg. Traduzione e validazione italiana [Rosenberg Self-Esteem Scale. Italian Translation and Validation]. Bollettino di Psicologia Applicata, 223, 35-44.

Ross, A., Paxton, S. J., \& Rodgers, R. F. (2013). Y’s Girl: Increasing Body Satisfaction among Primary School Girls. Body Image, 10, 614-618. https://doi.org/10.1016/j.bodyim.2013.06.009

Ryan, R. M., \& Deci, E. L. (2000). Self-Determination Theory and the Facilitation of Intrinsic Motivation, Social Development, and Well-Being. American Psychologist, 55, 68-78. https://doi.org/10.1037/0003-066X.55.1.68

Ryff, C. D. (2014). Psychological Well-Being Revisited: Advances in the Science and Practice of Eudaimonia. Psychotherapy and Psychosomatics, 83, 10-28. https://doi.org/10.1159/000353263

Sagone, E., \& Indiana, M. L. (2017). The Relationship of Positive Affect with Resilience and Self-Efficacy in Life Skills in Italian Adolescents. Psychology, 8, 2226-2239. https://doi.org/10.4236/psych.2017.813142

Scheier, M. F., \& Carver, C. S. (1985). Optimism, Coping, and Health: Assessment and Implications of Generalized Outcome Expectancies. Health Psychology, 4, 219-247. https://doi.org/10.1037/0278-6133.4.3.219

Srikala, B., \& Kishore Kumar, K. V. (2010). Empowering Adolescents with Life Skills Education in Schools-School Mental Health Program: Does It Work? Indian Journal of Psychiatry, 52, 344-349. https://doi.org/10.4103/0019-5545.74310

Su, R., Tay, L., \& Diener, E. (2014). The Development and Validation of the Comprehensive Inventory of Thriving (CIT) and the Brief Inventory of Thriving (BIT). Applied Psychology: Health and Well-Being, 6, 251-279.

https://doi.org/10.1111/aphw.12027

Wiese, C. W., Tay, L., Su, R., \& Diener, E. (2018). Measuring Thriving across Nations: Examining the Measurement Equivalence of the Comprehensive Inventory of Thriving (CIT) and the Brief Inventory of Thriving (BIT). Applied Psychology: Health and Well-Being, 10, 127-148. https://doi.org/10.1111/aphw.12119

World Health Organization (2003). Skills for Health, Information Series on School Health, Document Number 9.

Yeh, M. C., Liou, Y. M., \& Chien, L. Y. (2012). Development and Effectiveness of a School Program on Improving Body Image among Elementary School Students in Taiwan. Journal of Advanced Nursing, 68, 434-443. https://doi.org/10.1111/j.1365-2648.2011.05735.x 